\title{
VISUALIZACIÓN FOTOGRÁFICA Y PROYECCIÓN SOCIAL
}

Véronique Mondéjar 


\section{PHOTO DISPLAY AND SOCIAL SCREENING}

\section{RESUMEN}

El acto fotográfico incide en la realidad desde su intervención fragmentada, fundadora de criterios de construcción de identidad y mentalidad. Se establece a través de la representación fotográfica un impulso ecualizador de clases socioculturales, que consolida cierta jerarquía en las mentalidades de pueblos y gobernantes del mundo contemporáneo, concebido como espectáculo del consumo.

Palabras clave: fotografía, realidad, consumo, espectáculo.

\section{ABSTRACT}

The photographic act affects reality. A fragmented construction establishes criteria of identity and mentality. The photographic representation governs us and thus consolidates certain power of a sociocultural class hierarchy. This influence fixes certain mentalities of peoples and rulers of the contemporary world conceived as consumption show.

Keywords: Photographic representation, power, consumption, show.

\section{AUTORES}

\section{Véronique Mondéjar}

Docente y Directora de la Escuela de Artes

Universidad Nacional de Colombia, Sede Medellín

Correo electrónico: vcmondejarm@unal.edu.co 
Los comienzos de la fotografía posibilitaron que solamente dos tonalidades lograran ser el filtro cromático de su imaginario. La bicromía del blanco y negro es, ciertamente, alusiva al trazo de grafito del lápiz, lo que ha logrado definir el medio de reproducción más fiel de la realidad. La técnica fotográfica se desarrolló en sus inicios como perfeccionamiento del dibujo, considerándose como precursora ideológica (Cromer, 1925, p.477). Algunas de las primeras impresiones fueron fijadas sobre papel, en sepia azulado, técnica desarrollada por John Herschel en 1842 y denominada cianotipia debido al color del óxido del bromuro de plata. Hacer impresión sobre diferentes superficies era más fácil que fijarlas y, en los primeros intentos, las sales de platas, en su oxidación con el oxígeno del aire, ofrecieron gamas de ocres que se fueron enrojeciendo con el tiempo. Estos colores remiten a los lápices de sanguina o siena, que se utilizaron desde tiempos inmemoriales en el dibujo sobre papel o frescos en paredes y cavernas. Aquello que parece definir el médium fotográfico sigue remitiéndonos al dibujo y emana de la bicromía del blanco y negro.

El contenido documental está inmerso en toda fotografía, aunque dependa de la decisión del que oprime el botón. Es un gesto que adquiere sonido: un clic que deviene semántico, porque la imagen capturada habla de muchas más cosas que de la geometría espacial del encuadre. ¡Gesto de precisión con la energía ancestral del cazador! Visión mediatizada por el ojo del siglo que menciona Pierre Assouline (2002). Se van forjando certezas y testimonios visuales irrefutables que le otorgan al acto fotográfico valor de veracidad. Así, la fotografía filtra nuestros recuerdos e invita a conocer otras instancias, a imaginar universos desconocidos, por comprender. La imagen adquiere, según sus aplicaciones, una función social definida, porque existe un carácter documental que le otorga la apariencia de ser el instrumento de re- producción más fiel, más imparcial, de la vida social. No obstante, sigue siendo una creación capaz de recrear deseos e ilusiones, que distraigan a las masas de la ruda realidad y de sus inagotables problemas por resolver, a modo de iluminación de momentos de la historia de la sociedad burguesa de la época. Está escogida con el propósito de demostrar, a partir de ejemplos concretos. las relaciones que vuelven al arte y la sociedad dependientes el uno del otro. "La imagen y el espectador se parecen", afirma el catedrático francés Jacques Aumont (2002). Existe una relación implícita entre el fotógrafo y el que contempla la fotografía. Es esta unión la que va forjando lazos de aprehensión de la imagen desde las estructuras mentales investigadas por la escuela de la Gestalt. Conceptos como ilusión, duplicación o mímesis hablan del imposible intento de réplica del mundo físico. A fortiori, la fotografía no podría confundirse con la realidad retratada, sino que le son otorgados valores de apariencia. Así, la imagen fotográfica crea un horizonte virtual. La noción de representación adquiere un carácter retórico, cuyos estratos de significación son sedimentados por la Historia. Su representante ocupa el lugar de lo representado. Estos aspectos, por supuesto, favorecen que la imagen fotográfica se preste para la fetichización. Una verdadera antropología del espectador es mediatizada por las imágenes, siendo la fotografía el primer eslabón del medio de representación del universo.

Aunque los gustos o el carácter sociopolítico de cada época retratada se evidencian en diferentes formas artísticas, es a partir del Paleolítico cuando la especie humana se puso en la tarea de representar las cosas. Aparecen, entonces, unos senderos diferentes del de la presentación estética. Los eventos, las presas de caza o los animales míticos, tomaron la forma de objetos que han demostrado que la especie humana es capaz de abstraerse, a partir de los objetos cotidianos, en búsqueda de superficies 
representativas táctiles o visuales. Nace la imagen. Otra huella, esta más contemporánea, carga la imagen de sentido sin la intermediación humana: una fotografía puede dispararse sola, por accidente, o programándose el disparo sin la acción directa del operador, dando como resultado una imagen-objeto independiente del acto humano. Ambas son huellas de actividad más que producción representacional. Igualmente, pueden serlo las cámaras de seguridad en los condominios habitacionales, las empresas, los bancos, los aeropuertos, etc.: la fotografía como prueba de una presencia intrusa, peligrosa, que testifique una red de seguridad socio-cultural. El rol de la fotografía policial está presente desde los pioneros en el género de la fotografía vernácula, ayudando a fortalecer el halo de veracidad que toda imagen adquiere cuando testifica sobre un hecho pasado. Una de estas huellas ha logrado imponerse en las esferas culturales, por ser un médium que apela directamente a la memoria colectiva de pueblos y gobernantes. Se dibuja desde allí su rol histórico, que aparece como síntoma del ascenso al poder de la clase social burguesa, por el ansia de fijar en el curso de la historia su ascenso económico-social. Proyección o ilusión de la realidad son dualidades que van cimentando la noción de espectáculo. Esta noción se consolida a lo largo de las décadas comprendidas entre mediados del siglo XIX y principios del XX.

En el mismo instante de la aparición de una imagen en el visor de la cámara se establece el punto de vista como un momento de intuición creativa, como lo muestra esta fotografía de Cartier-Bresson. Simboliza una incursión en el aura lúdica de este medio.

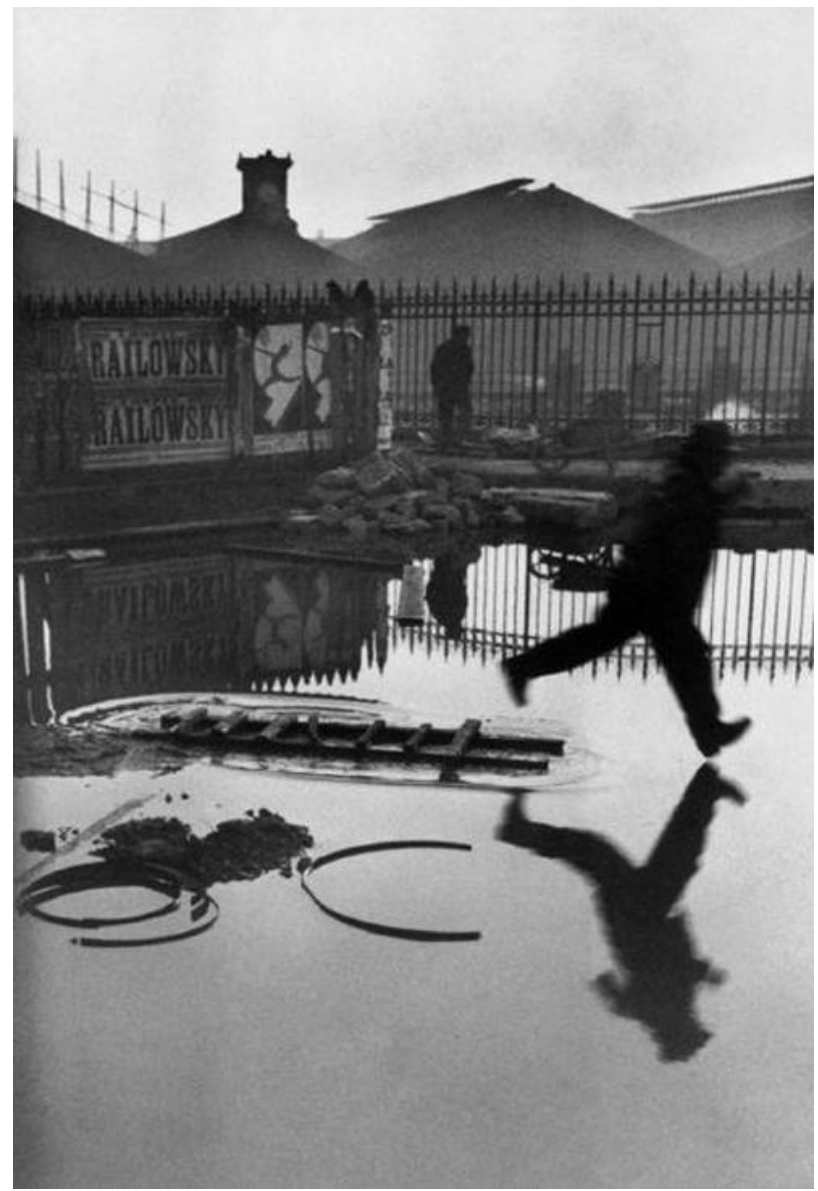

Imagen 1. Cartier-Bresson, Henry. Place de l'Éurope, Gare St Lazare. Fuente: http://pro.magnumphotos. com/C.aspx?VP3=CMS3\&VF=MAG031_10_ VForm\&ERID=24KL53ZMYN

En esta celebre fotografía se destaca la habilidad de captar la temporalidad. Este personaje salta al vacío, se congela su pose mientras subraya la noción de equilibrio. En el plano inferior resalta su reflejo y abre así un espacio fuera de lo común en la representación fotográfica convencional, pues 
se supone que, al caer, este cuerpo hará estallar en mil pedazos este trozo de realidad, el piso que recibirá, o no, este futuro impacto corporal. Congelar el instante es la aportación plástica que nos lega Cartier- Bresson, una visión que ahora parece intrínseca al acto de la toma de vista. Este hecho pone a dialogar el concepto de visualización con los lazos estrechos existentes entre arte y sociedad. Más que la mera técnica de impresión de la realidad, importa cómo esa fotografía nos relaciona con lo demás. El hecho fotográfico se contempla, desde allí, no como la imagen resultante de una técnica, sino como una cultura de la visión, la del acto creativo del fotógrafo. Esta posibilidad de captura instantánea creó tantos adeptos en el universo de la fotografía de aficionados. Sus imágenes fueron convirtiendo la fotografía en testimonio visual de la era industrial.

Sin embargo, pareciera que esta visualización se limitara a una visión central, de Cíclope, porque, aunque se considere que la fotografía es un instrumento idóneo para conocer otras instancias sociológicas, la óptica geométrica de solo dos planos nos lleva a aniquilar otros sentidos de aprehensión de la realidad. Así, la fotografía va adquiriendo una función social que se relaciona con un aspecto documental intrínseco: el instrumento de reproducción más fiel, más imparcial de la vida social. A pesar de estas características, la fotografía se vuelve un medio de creación capaz de recrear deseos, procrear ilusiones susceptibles de distraer a las masas de su cotidianidad. El momento Kodak queda fijado en un instante y para siempre. En este sentido, podemos afirmar que nuestra conciencia, nuestras expectativas, nuestra sensibilidad, lo que proyectamos como esperanzas de futuro, están determinados, metafóricamente, de alguna manera, por aquello que significa la fotografía. Esta ha sido un puente magnífico entre el siglo XIX y el siglo XXI. El siglo XIX ha inventado un concepto de realidad que todavía manejamos; el XXI, seguramente, será el siglo de la ilusión, de lo virtual. La fotografía se ha movido, justamente, entre esos conceptos, el de realidad y el de virtualidad o ilusión. Por esto, el trabajo de todo fotógrafo, sea consciente o no, se mueve entre dos mitos: el mito de que toda fotografía es real y el mito de que toda fotografía es incierta, como lo menciona el fotógrafo Joan Fontcuberta. (Formiguera y Fontcuberta, 2002).

Usualmente, así en fotografía como en otras expresiones artísticas, lo tradicional o lo predecible enmascaran lo novedoso o lo experimental. Las barreras culturales, formadas por editores, galeristas, críticos y otros patrocinadores, representan factores decisivos. Las realizaciones que trascienden socialmente validan los géneros. Se crean categorías, se establecen jerarquías genéricas: retratos, desnudos, paisajes y bodegones en la categoría artística. La fotografía documental se divide en reportaje y fotoperiodismo. Los disidentes se preocupan únicamente por la experimentación creativa, alejando, a menudo, el éxito económico de sus proyectos. Impulsados por la aspiración de expandir el lenguaje del médium, estos autores toman riesgos. Los logros adquiridos, tanto expresivos como técnicos, son empujados por estos experimentadores. Este deseo de captar lo implícito, lo oscuro, va formando un imaginario fotográfico genuino. Se suele decir que el arte empuja las fronteras del médium, tanto técnicas como expresivas.

Se establece una competencia en el campo icónico, entre lo pictural y lo fotográfico. Es usual referirse a la fotografía como un arte que no posee sentido en sí mismo, un arte intermedio como lo denomina el sociólogo Pierre Bourdieu, un arte que no significa, sino que es un fiel reflejo de lo real (Bourdieu, 1979). Es así como la fotografía, utilizada por otras disciplinas, deviene en una herramienta de conocimiento, de diagnóstico, en medicina, etnología, ciencias, información, entre otros, porque esta imagen se convierte en un 
medio fiable de conocimiento de lo real circundante, ya que no se cuestiona su fiabilidad como medio directo de observación del entorno, alrededor del cual muchas actividades humanas confluyen.

Siguiendo estos senderos cognitivos, también podemos considerar la fotografía de archivo como un instrumento para conocer otras instancias, imaginar universos por comprender. Sin embargo, pocas son las fotografías que perduran en las memorias colectivas, de modo que lleguen a comunicar la esencia, como lo logra hacer el arte. Mirar la historia de la fotografía con estos propósitos sitúa la imagen en un paradigma entre veracidad histórica e interpretación expresiva del mismo médium. Con esto, se constatan dos perspectivas disimiles: historia y arte. Para el historiador, la fotografía es un instrumento de estudio de la finalidad sociológica. Para el artista, la fotografía es un proceso en elaboración continua. Sin embargo, tanto para el aficionado como para el profesional, pareciera difícil no sucumbir a una especie de bulimia consumista de imágenes. Los avances incesantes de la técnica y el abaratamiento de costos de producción han facilitado la toma de vista y, lo que fuera el laboratorio analógico, se ha incorporado a la cámara digital y a la telefonía inteligente, que irradió y modificó la comunicación social, en todas las esferas de la relaciones humanas, poniendo al alcance de un clic el desfile incesante de ensayos y hallazgos fotográficos.

Las teorías modernas de la representación, elaboradas a partir del tronco común de lo analítico y de la fenomenología, han rechazado que una imagen sea considerada como un plano que se puede ver como un paisaje. Sin embargo, existen diferencias entre una imagen que representa un paisaje y lo figurado en él. Esto significa que no se puede pensar de la misma manera un cuadro y su visión. Así lo expone la tesis cartesiana fundamental de la dioptrique. La visión es una imagen que no se puede ver porque es siempre la ilusión de alguien. Las teorías modernas de la representación privilegian la relación entre el objeto y su representación dentro del cuadro, tal como en su visión. Representación del objeto y objeto de representación son las dos vertientes de lo objetivo y lo subjetivo.

A menudo, se obvia que pueden existir representaciones sin sujetos, que vienen a serlo bajo forma de objeto. Podemos imaginar establecer nuevas relaciones entre la forma en su sentido artístico y lo ontológico. ¿Cómo se emplaza la fotografía en el proceso de construcción de la noción de veracidad testimonial? Porque la fotografía puede manipular objetos como formas de presentación del presente, cosas existentes o puestas en escena, igual que cosas ausentes. En una fotografía, la luz fijada en una superficie aparece como un vacío que da forma a caras, calles, paisajes, que sabemos ausentes pero que percibimos como vividos. No se trata de una perspectiva únicamente convencional, porque este fenómeno no constituye, de antemano, una regla cultural. Hay que distinguir el concepto de representación de la idea clásica de mímesis, pero también de la idea moderna de significación, como lo sostiene Charles Sanders Peirce (1978). Si bien la fotografía no podría confundirse con la realidad retratada, a menudo se le otorgan valores de apariencia. Así, la imagen fotográfica crea un horizonte virtual. La noción de representación adquiere un carácter retórico cuyos estratos de significación son sedimentados por la historia. Su representante ocupa el lugar de lo representado. En oposición a lo expresado por toda teoría mimética, representar no se limita a la producción de una copia, puesto que una obra puede representar algo ausente.

La significación, por el contrario, es una operación que incluye un intérprete, pues pone en relación un 
signo y un objeto. La fotografía del humo no es el signo del fuego, porque tiene que existir una representación previa, por hábitos o por experiencia, para que se comprenda el signo, mas no la fotografía.

La diferencia entre signo y representación radica en que el primero puede variar, sin afectar lo que significa, mientras que una representación no puede ser afectada sin perturbar aquello que representa. Significar es, entonces, asociar un signo a un objeto por el intermediario de uno o más signos. Representar es acordar una presencia a una ausencia y viceversa; "En el signo, la presencia se esfuma detrás de la relación: en la representación no hay más nada que una relación entre lo presente y lo ausente" (Debray, 1997).

Las diferencias entre la realidad y la fotografía trasfieren la cuestión a la noción de lo documental, al andamiaje epistemológico. Este atributo emerge porque coexiste un parecido muy cercano con la percepción diaria del mundo, alejándose, así, de formas como la pintura, el dibujo y la escultura. A pesar de reconocer al sujeto de una imagen fotográfica, se permiten distorsiones codificadas, como la ausencia de color, un ángulo peculiar de vista o una ausencia de luz. Partir de la luz es una opinión defendida, también, de manera distinta, que muestra cómo la tradición del pensamiento, desde Platón, basa la epistemología de la filosofía occidental en el fenómeno lumínico (Blumenberg, 2008). Estas diferencias desaparecen cuando la representación muestra, más que una interpretación distintiva, la esencia de lo retratado. Existe, sin embargo, un aura que transciende el perfil hipotético del campo investigativo. Evidentemente, toda representación está abierta a la interpretación y puede ciertamente ser utilizada como signo.

En la mímesis, la representación es una relación entre objeto y forma. Estas reflexiones se enraízan en el contexto sociológico contemporáneo de la noción de espectáculo. Este refiere a un espacio que se crea a lo largo de las décadas comprendidas entre mediados del siglo XIX y principios del XX, en el cual los espectáculos ilusionistas han servido de excusa para burlar la misma credibilidad, capaz de generar la captación de esta ilusión de realidad que provoca el invento de la fotografía. Las nociones de realidad y su relación con el referente socio-cultural relatado en la historia posicionan la imagen en una encrucijada. La imagen fotográfica es fundadora de criterios de construcción de identidad. Sin embargo, existe una brecha entre veracidad testimonial y construcción de la noción de documento histórico. El análisis iconológico localiza este debate en la esfera de la interpretación. Lo que se busca es localizar la noción de significado que va dibujando su propio contenido. Entre veracidad testimonial y documento histórico, la fotografía va fijando criterios de construcción de identidad por los cuales se puedan localizar la nociones de significado y contenido en la interpretación y definir tres lazos interpretativos de la imagen: lo iconológico, lo interpretativo y sus valores.

Desde el punto de vista de la teoría de la significación, toda representación es significante y se presta a una interpretación. Todos los medios de representación pasan por medios objetivos, como la perspectiva, la profundidad de campo o las proporciones; es decir, medios construidos, interpretativos, que toman sentidos nada más que bajo la mirada de una visión acostumbrada: "No representan inmediatamente lo real porque necesitan de un intérprete" (Panofsky, 1976, p.35). El fotógrafo ha de captar una situación ambientada, que transmita una atmósfera que logre superar la realidad de los objetos. De aquí la magia de la fotografía, cuyo poder de convicción logra transformar la realidad.

El medio de información y comunicación influye para formar una noción histórica de realidad. El espectador mediatizado consulta el mundo visual en los 
periódicos, los libros, los álbumes, los archivos o las colecciones de fotos. Desde este pedestal ejercemos como público privilegiado, porque se suelen emitir juicios constantes que van forjando una apreciación, a veces de modo inconsciente. Estamos acostumbrados, desde nuestra posición de consumidores de imágenes, a examinar la sociedad con ojos de experto. Asumimos el rol de connaisseur. Se acepta, así, como espejo propio una idea o un gusto que sentimos que nos va a pertenecer poco a poco. La fotografía verifica con una imagen lo que se materializa en un primer momento de intuición, no ausente de las nociones de producto y consumo. La imagen consume el mundo que se corrige, se manipula o recrea, según los intereses de los diferentes núcleos comunicacionales de los usuarios de cada red social.

A partir de estas reflexiones, se puede concluir que, en la era tecnológica, la representación reagrupa en gran parte la dimensión psicológica, desde su elaboración en una conciencia o en un sistema perceptivo. La virtualización mediática consiste en una realidad cuya escala implosiona a partir de la imagen fotográfica. En la era contemporánea, la creencia en el objeto mediático transforma la percepción del entorno y la inserción del sujeto en su perspectiva misma. "De quién son estos ojos que están viendo" se podría preguntar, como lo hace tantas veces el poeta Fernando Pessoa. Sin embargo, el resultado de querer fijar el instante nunca está ausento de valores o nociones de producto y consumo. Existen, simultáneamente, objetos y acontecimientos. Mientras que los objetos son cosas que representan lo fotografiado, los eventos son presencias de estas cosas o presencias de objetos. Un evento sería una presencia de las cosas en el mundo. Desde un punto de vista estético, "lo ilusorio transciende lo verdadero", como lo afirma Jacques Morizot (Morizot, 2008, p.2). En este sentido, objetos y acontecimientos se vuelven similares, pertenecen al mismo régimen, el sistema objetivo, el de la acumulación. No obstante, objetos y eventos son equivalentes en el universo de las cosas, sin pertenecer por este hecho a la misma categorización. Las cosas son formales porque desvelan ausencia o presencia, que triangulan sus relaciones estéticas cuando están mediatizadas por la técnica fotográfica.

Por otro lado, la condición actual del desarrollo tecnológico-virtual establece nuevas relaciones socioculturales que posicionan nuevos valores como la globalización, la simultaneidad o la atemporalidad del uso masivo de la imagen. Es la técnica fotográfica la que representa el eslabón inicial de la nueva esfera de conocimiento. Con su lema "Press the button, we do the rest”, "¡Por un dólar!”, Kodak revolucionó la representación de la cotidianidad. Hoy le debemos este incesante bombardeo de vistas que han hecho de lo representado algo protagónico, digno de ser compartido en directo.

Así se aprecia la manera en que una fotografía teje, a partir de la espontaneidad de l'instant décisif, un verdadero simulacro socio-cultural. Lo registrado sella una irrefutable visión personal que se queda en la memoria como documento objetivo. Por este acto, las imágenes devienen objetos cuyas formas fijan valores en la visión de la cultura de consumo que nos rige. Con su intervención fragmentada, marca los momentos Kodak de nuestra vida diaria, donde la sonrisa capturada por la instantánea del amateur y sus innumerables selfies aún revelan aquel detalle anodino y le otorgan al médium "valores indiscriminados en la jerarquía psicológica del mundo contemporáneo del espectáculo" (Deborde, 2000). En destellos de flash, se fragmenta una visión que deviene visualización y proyección social, en un automatismo inconsciente que se va integrando en la mentalidad del ser contemporáneo. 


\section{REFERENCIAS}

Assouline, P. (2002). Cartier-Bresson: el ojo del siglo. Paris: Galaxia Gutenberg.

Aumont, J. (2002). La imagen. Buenos Aires: Paidós.

Blumenberg, H. (2008). La legitimación de la edad moderna. Valencia: Pre-textos.

Castel, R. (1979). "Imágenes y fantasma". En: P. Bourdieu, Compilador. La fotografía: un arte intermedio (p. 354). Editorial Nueva Imagen. México.

Cromer, G. (1925, octubre). "Le secret du physionotrace, la curieuse machine à dessiner". En: Bulletin de la Société du Vieux Papier. pp. 477-484.

Debord, G. (2000). “La sociedad del espectáculo”. En: Observaciones filosóficas. pp. 27.

Debray, R. (1992). Vie et mort de l'image. Une histoire du regard en occident. Paris: Gallimard.

Debray, R. (1997). Transmitir. Editorial Manantial: Buenos Aires.

Formiguera, P. y Fontcuberta, J. (2002, noviembre). “Fauna: los trucos del mago". En: Foto, 239.

Morizot, J. (2008, noviembre). "Illusion, trompe-l'oeil, simulation." En: Révue Française d'Esthétique, 3, 2.

Panofsky, E. (1976). Estudios sobre iconología. Madrid: Alianza Editorial.

Peirce Sanders, Ch. (1978). Écrits sur le signe. Paris: Le Seuil. 